\title{
CARACTERIZACIÓN Y CLASIFICACIÓN DE HATOS LECHEROS EN COSTA RICA MEDIANTE ANÁLISIS MULTIVARIADO ${ }^{1}$
}

\author{
Bernardo Vargas-Leitón ${ }^{2}$, Oscar Solís-Guzmán ${ }^{2}$, Fernando Sáenz-Segura ${ }^{3}$, Héctor León-Hidalgo ${ }^{4}$
}

\section{RESUMEN}

Caracterización y clasificación de hatos lecheros en Costa Rica mediante análisis multivariado. Esta investigación se realizó con el objetivo de caracterizar y clasificar un conjunto de hatos afiliados a la Cooperativa de Productores de Leche Dos Pinos R.L de Costa Rica. La información analizada se obtuvo del último censo realizado por la cooperativa en el año 2007. Se complementó con registros comerciales computarizados de la misma empresa y sistemas de información geográfica con datos climáticos y tipos de suelo. La clasificación de los hatos se realizó mediante dos técnicas de análisis multivariado: el Análisis de Factores (AF) y el Análisis de Conglomerados (AC). Las dieciocho variables observadas comprendieron principalmente aspectos físicos y climáticos de la finca, variables de manejo, nivel de uso de insumos y de producción. El AF identificó tres factores principales: el nivel de intensificación, el piso altitudinal, y la orientación productiva que retienen un 42,6\%, 24,2\% y $13,3 \%$ de la varianza observada. Con base en estos tres factores el AC identificó cinco tipologías principales de hatos: lechería especializada intensiva de altura $(n=374)$, lechería especializada semi-intensiva de altura $(n=274)$, lechería especializada intensiva de bajura $(n=167)$, lechería especializada extensiva de bajura $(n=189)$ y lechería doble propósito extensiva de bajura $(n=82)$.

Palabras claves: análisis de factores principales, método de Ward, ganado lechero.

\begin{abstract}
Characterization and classification of dairy herds using multivariate analysis in Costa Rica. This study was carried out to characterize and classify a group of herds $(n=1086)$ associated to the main Dairy Cooperative in Costa Rica. The information analyzed in this study was obtained initially from the last census conducted by the cooperative during year 2007. This information was complemented with computerized records of the same cooperative and geographical information systems with climatic and soil types data. Farm classification was performed by combining two different multivariate techniques: Factor Analysis (FA) and Cluster Analysis (CA). Analysis was performed on 18 variables, mainly related to physical and climatic aspects, herd management, input level and production level. FA identified three significant principal factors: intensification level, altitude (masl), and productive orientation accounting for $42,6 \%, 24,2 \%$ and $13,2 \%$ of total variance. On the basis of these three factors, CA identified five main herd typologies: Intensive specialized dairy herds in the highlands $(n=374)$, Semi-intensive specialized dairy herds in the highlands $(n=274)$, Intensive specialized dairy herds in the Lowlands $(n=167)$, Extensive specialized dairy farms in the Lowlands $(n=189)$ and Extensive Dual-Purpose herds in the Lowlands $(n=82)$.
\end{abstract}

Keywords: principal factors analysis, Ward method, dairy cattle.

\footnotetext{
Recibido: 19 de febrero, 2013. Aceptado: 28 de octubre, 2013. Este estudio se realizó dentro del marco del proyecto de investigación SIA 0050-11, Universidad Nacional, Heredia, Costa Rica.

2 Posgrado Regional en Ciencias Veterinarias Tropicales, Universidad Nacional, Costa Rica. Apdo. Postal 304-3000. bernardo.vargas.leiton@ una.cr, osolisguzman@ina.ac.cr

3 Centro Internacional de Política Económica para el Desarrollo Sostenible (CINPE), Universidad Nacional, Costa Rica. Apdo. Postal 23933000. fernando.saenz.segura@una.cr

4 Programa de Transferencia Tecnológica, Cooperativa Dos Pinos, sede Alajuela, Costa Rica. Apdo. Postal 179-4060. hleon@dospinos.cr
} 


\section{INTRODUCCIÓN}

La actividad lechera en Costa Rica ha estado en constante crecimiento y desarrollo durante las últimas décadas. En el año 2011 se produjeron aproximadamente 966,3 millones de litros de leche procedentes de 16125 hatos de lechería especializada y doble propósito (Camacho-Sandoval 2012, SEPSA 2012). Esto representó un incremento del 1,5\% con respecto al 2010. En el mismo año, la actividad lechera contribuyó con el 11,1\% del valor agregado de las principales actividades primarias del sector agropecuario, siendo superada solamente por el café y el banano (SEPSA 2012). El sector lechero integrado genera $200000 \mathrm{em}$ pleos directos o indirectos (Camacho-Sandoval 2012). Lo anterior, refleja el importante impacto que tiene esta actividad sobre el desarrollo rural, la generación de empleo y la seguridad alimentaria.

Los hatos lecheros de Costa Rica se ubican principalmente en zonas que van desde los 500 hasta los $2500 \mathrm{msnm}$ con temperaturas promedio que oscilan entre los 18 y $30^{\circ} \mathrm{C}$ y niveles de precipitación que van desde los 500 hasta $3500 \mathrm{~mm}$ por año. Tradicionalmente, los sistemas de producción de leche en Costa Rica se han clasificado en tres grupos: las lecherías especializadas de altura, las lecherías especializadas de bajura y los hatos de doble propósito (Vargas-Leitón 2000, González-Echeverría 2012). Esta clasificación, sin embargo, no refleja a cabalidad la diversidad existente actualmente en los sistemas de producción, donde se encuentra gran variación en aspectos tales como sistemas de confinamiento, tipos raciales, nivel de uso de tecnologías, manejo de recurso forrajero, uso de suplementos y concentrados, mano de obra, etc. Es necesario caracterizar de una manera más precisa y objetiva los diferentes grupos o estratos de hatos. Esta clasificación es importante por varias razones, entre ellas, porque permite la evaluación y comparación de niveles de competitividad dentro de estratos homogéneos y además permite identificar fortalezas y debilidades en cada estrato, lo que a su vez facilita el desarrollo e implementación de políticas orientadas a distintos grupos meta según sus necesidades específicas (Köbrich et al. 2003, Gaspar et al. 2007, Mburu et al. 2007).

La caracterización significa identificar las principales variables que inciden en el grado de heterogeneidad y homogeneidad existente entre las explotaciones ganaderas de una determinada región, generando grupos representativos de subsistemas productivos (Valerio-Cabrera et al. 2004). Una de las formas más objetivas para identificar grupos homogéneos de entidades son las técnicas de análisis multivariado, tales como el Análisis de Factores y el Análisis de Conglomerados (Hair et al. 1998, Johnson y Wichern 1998).

El Análisis de Factores (AF) es una técnica generalmente utilizada para reducir dimensionalidad, es decir, eliminar información redundante contenida en un conjunto amplio de variables y simplificarla en un número reducido de dimensiones o factores con propiedades óptimas para la interpretación de la variabilidad y covariabilidad subyacente (Johnson y Wichern 1998). De esta manera el AF permite descubrir patrones que no son evidentes en las variables originales.

El Análisis de Conglomerados (AC) es una técnica para organizar o clasificar múltiples entidades, por ejemplo, hatos lecheros, en un número reducido de grupos, normalmente denominados taxonomías o tipologías, con base en información multivariada procedente de diversas fuentes (Hair et al. 1998).

Varios estudios han reportado el uso de estas técnicas con fines de caracterización de sistemas de producción agrícolas o ganaderos. La mayoría de estos estudios consideran variables estructurales, así como parámetros técnicos, económicos o productivos (Köbrich et al. 2003, Srairi y Lyobi 2003, Betancourt et al. 2005, Gaspar et al. 2007, Mburu et al. 2007, Giorgis et al. 2011, Gelasakis et al. 2012, Martínez-García et al. 2012). Algunos de ellos incluyen además aspectos sociológicos, tales como el nivel de educación o la experiencia de los productores (Solano et al. 2000, Solano et al. 2003, Avilez et al. 2010, Gelasakis et al. 2012, Martínez-García et al. 2012). En Costa Rica, solo un estudio reporta el uso de análisis de factores para estudiar el proceso de toma de decisiones en un grupo de 91 productores de leche (Solano et al. 2003).

Algunos aspectos identificados por varios de estos estudios son la orientación productiva, el nivel de productividad o el nivel de uso de alimentos concentrados (Srairi y Lyobi 2003, Serrano-Martínez et al. 2004a, Avilez et al. 2010), los cuales ayudan a caracterizar y agrupar las fincas. Las variables físicas o estructurales, tales como el tamaño de la empresa o la cantidad y tipo de animales también han resultado de importancia (Avilez et al. 2010, Martínez García et al. 2012).

El presente estudio tiene por objetivo caracterizar y clasificar los hatos lecheros agremiados a la Cooperativa 
de Productores de Leche Dos Pinos R. L de acuerdo con variables agroecológicas, socioeconómicas y técnicas. La agrupación obtenida será utilizada en un estudio posterior que evaluará los factores que afectan la eficiencia técnica en hatos lecheros.

\section{MATERIALES Y MÉTODOS}

\section{Población bajo estudio}

El universo de estudio lo conformó un total de 1086 hatos lecheros agremiados a la Cooperativa de Productores de Leche Dos Pinos R.L. La mayoría de estos hatos se ubicaron en las zonas aledañas a los macizos montañosos de la Cordillera Volcánica Central, principalmente en las zonas agroecológicas denominadas bosque muy húmedo (tropical, premontano, montano bajo, montano o pluvial) y bosque húmedo (tropical) según la clasificación de Holdridge (1987). Estas zonas agroecológicas se encuentran dispersas mayormente en las regiones socioeconómicas Huetar Norte y Central, que incluyen las provincias de Alajuela, Heredia, San José y Cartago, así como la región Chorotega en la provincia de Guanacaste.

El estudio realizado fue de tipo observacional y retrospectivo. La información analizada se obtuvo mayormente del último censo realizado por la cooperativa durante el año 2007, en el cual se indagó sobre aspectos relacionados con variables físicas y agroecológicas de la finca, inventarios de animales, manejo nutricional, uso de mano de obra, tipo de pasturas, uso de fertilizantes y administración. Paralelamente se contó con registros automatizados de cantidad y calidad de la leche entregada por cada productor, expresados como promedio de las 52 semanas del año. Se contó también con información complementaria de registros comerciales automatizados de la empresa, detallando las ventas de alimento concentrado de diversos tipos, como promedio de 52 semanas anuales, a los productores afiliados. Además de geoposicionamiento de los hatos, los cuales se utilizaron en combinación con mapas digitalizados de suelos, modelos de elevación digital y datos climatológicos de temperatura y precipitación, con el fin de obtener estimaciones puntuales de estas variables para cada hato.

\section{Análisis de la información inicial}

La información colectada mediante el censo y los registros de la empresa permitieron identificar un total de 56 variables. Con base en el procedimiento recomendado por Hair et al. (1998) se realizó una estandarización y agregación de estas variables, con el fin de mejorar y simplificar la estructura de los datos antes de la implementación de los análisis multivariados. De esta manera, subgrupos de variables relacionadas con un mismo insumo o producto fueron agrupadas para formar variables compuestas. Esto se realizó por ejemplo con los diferentes tipos de concentrados, suplementos, fertilizantes, componentes lácteos, inventarios de distintos tipos animales o tiempo de mano de obra para distintas actividades.

Se obtuvieron dieciocho variables (Cuadro 1), de las cuales quince fueron de tipo cuantitativo $\mathrm{y}$ tres fueron de tipo cualitativo jerárquico. Para efectos de estandarización, seis de las variables de tipo cuantitativo fueron re-codificadas dividiendo entre el número de hectáreas dedicadas al hato en producción. Las variables de área total de pastos y área dedicada a forraje de corta, también fueron expresadas en proporción al área dedicada al hato en producción.

Las variables de tipo cualitativo fueron codificadas en orden jerárquico. Por ejemplo, la orientación productiva se codificó de menor $(0$, doble propósito) a mayor (1, lechería especializada) actividad lechera.

Las categorías de suelo fueron codificadas de acuerdo con su potencial agrícola. Por ejemplo, la clase 1 agrupó a los suelos de tipo ultisol y alfisol, que son suelos degradados y de baja fertilidad, mientras que la clase 4 correspondió a los suelos inceptisoles, considerados como de alto potencial agrícola (Cabalceta-Aguilar 2012).

De igual manera los sistemas de confinamiento se escalonaron de menor a mayor grado de estabulación. La clase 1 correspondió a hatos manejados en pastoreo a lo largo de todo el año, las clases 2 y 3 combinan el pastoreo con periodos estacionales cortos de semiestabulación o estabulación parcial. Las clases 4 y 5 correspondieron a sistemas continuos de semiestabulación o estabulación. 
Cuadro 1. Variables, códigos y categorías (o escalas de medición) conformadas para la caracterización de hatos lecheros. Costa Rica, año 2007.

\begin{tabular}{|c|c|c|}
\hline Variable & Código & Categoría o escala de medición \\
\hline \multirow[t]{2}{*}{ Orientación productiva } & ori_pro & 0 Doble propósito \\
\hline & & 1 Lechería especializada \\
\hline \multirow[t]{5}{*}{ Sistema de confinamiento ${ }^{1}$} & sis_con & 1 Pastoreo todo el año \\
\hline & & 2 Pastoreo y semiestabulado \\
\hline & & 3 Pastoreo y estabulación parcial \\
\hline & & 4 Semiestabulado todo el año \\
\hline & & 5 Estabulación todo el año \\
\hline \multirow[t]{4}{*}{ Tipo de suelo ${ }^{2}$} & tip_sue & 1 Ultisoles y alfisoles \\
\hline & & 2 Vertisoles \\
\hline & & 3 Andisoles \\
\hline & & 4 Inceptisoles \\
\hline Nivel de precipitación ${ }^{3}$ & niv_prc & mms anuales \\
\hline Temperatura ambiental promedio ${ }^{3}$ & tem_amb & grados centígrados \\
\hline Piso altitudinal ${ }^{3}$ & pis_alt & metros sobre el nivel del mar \\
\hline Área total de pasturas & are_pas & (ha pasto)/(ha prod) \\
\hline Área de forraje de corte & are_for & (ha corte)/(ha prod) \\
\hline Uso de fertilizantes & uso_fer & $\mathrm{kg} \mathrm{sem} / \mathrm{ha}$ \\
\hline Uso de mano de obra ${ }^{4}$ & uso_obr & peones/ha \\
\hline Horas de gestión administrativa & hrs_adm & hrs/ha \\
\hline Uso de alimentos concentrados ${ }^{5}$ & uso_con & $\mathrm{kg} \mathrm{sem} / \mathrm{ha}$ \\
\hline Uso de alimentos suplementarios ${ }^{6}$ & uso_sup & $\mathrm{kg} \mathrm{sem} / \mathrm{ha}$ \\
\hline Carga animal $^{7}$ & car_ani & vacas en producción/ha \\
\hline Porcentaje de ganado especializado ${ }^{8}$ & pct_esp & $\%$ \\
\hline Conteo de células somáticas & con_cel & $\mathrm{cel} / \mathrm{ml}$ \\
\hline Conteo bacterial en leche & con_bac & UFC \\
\hline Producción de sólidos totales & kgs_sol & $\mathrm{kg} \mathrm{sem} / \mathrm{ha}$ \\
\hline
\end{tabular}

${ }^{1}$ Categorizado en escala ascendente de acuerdo al grado de confinamiento.

${ }^{2}$ El tipo de suelo para cada hato se asignó con base en su posición geográfica, obtenida por GPS, en combinación con el mapa digitalizado de suelos de Costa Rica (Cabalceta-Aguilar 2012). Las categorías se ordenaron aproximadamente en escala ascendente según estructura y fertilidad del suelo.

${ }^{3}$ Las variables de precipitación, temperatura y piso altitudinal para cada hato se obtuvieron por métodos de interpolación con base en su posición geográfica, obtenida por GPS, en combinación con datos climatológicos digitalizados de estaciones meteorológicas a nivel nacional y modelos digitales de elevación.

${ }^{4}$ Sumatoria de trabajadores en labores de ordeño y peones campo.

${ }^{5}$ Sumatoria de nueve tipos de concentrado de uso común en hatos lecheros.

${ }^{6}$ Sumatoria de nueve tipos de suplemento de uso común en hatos lecheros.

${ }^{7}$ Obtenida como número de vacas en edad adulta dividida sobre el área dedicada al hato en producción.

${ }^{8}$ Razas especializadas más frecuentes: Holstein, Jersey, Pardo Suizo, Guernsey, Ayrshire. Se contabilizan también los cruces entre estas mismas razas. 


\section{Análisis estadístico descriptivo}

Se obtuvieron estadísticos de tendencia central y dispersión para las variables de tipo cuantitativo, así como distribuciones de frecuencia para las variables de tipo cualitativo.

La información anterior se sometió a un proceso de edición basado en análisis estadístico, utilizando el programa de computación SAS, versión 9.2 (SAS Institute Inc 2008) con el fin de detectar valores extremos biológicamente improbables, utilizando como criterio distribuciones de probabilidad (por ejemplo distribución normal, promedio \pm 3 desviación estándar). Los valores identificados como improbables se asumieron como datos faltantes y las observaciones respectivas no se utilizaron en análisis posteriores. Adicionalmente, en los casos donde existió información común a ambas fuentes (hato y empresa), se realizó un control cruzado de la información dando prioridad en caso de duda a los registros automatizados de la empresa, por ser esta una fuente más precisa y confiable.

\section{Análisis estadístico multivariado}

Con el fin de caracterizar y clasificar los hatos, se utilizaron dos técnicas de análisis multivariado: el Análisis de Factores (AF) y el Análisis de Conglome$\operatorname{rados}(\mathrm{AC})$.

Para el AF se utilizó el procedimiento FACTOR del programa estadístico SAS, versión 9.2 (SAS Institute Inc 2008). Se exploraron varios métodos de extracción de factores, seleccionando finalmente el método de Factores Principales (Hair et al. 1998, Johnson y Wichern 1998). El procedimiento requiere de la especificación de valores previos de comunalidad para cada variable, los cuales se estimaron a partir del valor máximo de correlación absoluta de cada variable observada con cualquiera de las demás. Se exploraron varios métodos de rotación oblicuos y ortogonales, seleccionando al final el método de rotación ortogonal Varimax (Hair et al. 1998, Johnson y Wichern 1998), el cual mantiene la independencia entre los factores, lo que representa una propiedad importante para el posterior análisis de conglomerados.

Se obtuvieron y graficaron las correlaciones o cargas entre cada uno de los factores y las variables observadas. Para determinar el número mínimo de factores necesarios se consideró inicialmente seleccionar factores con raíces latentes (autovalores) mayores que uno (Hair et al. 1998). Se procuró además que la proporción acumulada de varianza explicada por los factores extraídos fuera superior a $75 \%$.

Una vez seleccionados los factores, se procedió a realizar un Análisis de Conglomerados (AC) (Hair et al. 1998, Johnson y Wichern 1998). Las variables observadas iniciales fueron sustituidas por las puntuaciones factoriales (Hair et al. 1998) calculadas para cada hato utilizando solamente los factores principales extraídos en el procedimiento anterior (AF).

El AC se realizó siguiendo una estrategia de dos fases, según se sugiere en varios estudios previos (Giorgis et al. 2011, Nainggolan et al. 2011, Gelasakis et al. 2012). En la primera fase se utilizó el método de agrupación jerárquico de Ward (Hair et al. 1998, Johnson y Wichern 1998), con el fin de determinar un número óptimo preliminar de grupos a formar. Se exploraron niveles de agrupación progresivos desde 3 hasta 15 grupos y el nivel óptimo se definió con base en la evaluación conjunta del Criterio de Clusterización Cúbica (CCC), el valor del Pseudo t ${ }^{2}$, el valor de Pseudo F y el $\mathrm{R}^{2}$ (SAS Institute Inc 2008). El nivel de agrupación óptimo se obtiene cuando se combinan picos locales de CCC, un valor alto de Pseudo F y un valor bajo de Pseudo $\mathrm{T}^{2}$, junto con un valor alto (por ejemplo $>70 \%$ ) para $\mathrm{R}^{2}$ (SAS Institute Inc 2008). Para esta fase se utilizó el procedimiento CLUSTER implementado en el programa estadístico SAS, versión 9.2 (SAS Institute Inc 2008). En la segunda fase del AC, se procedió a obtener la agrupación definitiva de los hatos utilizando el método no jerárquico $K$-means (Hair et al. 1998, Johnson y Wichern 1998), especificando como punto de partida el número de conglomerados identificado como óptimo en el paso anterior. Para esta fase se utilizó el procedimiento FASTCLUS implementado en el programa estadístico SAS, versión 9.2 (SAS Institute Inc 2008).

Una vez obtenidos los conglomerados se procedió a su caracterización. De acuerdo con Daniel (2002) para las variables cuantitativas, se realizaron análisis de varianza univariados especificando cada variable original como dependiente $(\mathrm{Y})$ y el conglomerado como factor independiente $(\mathrm{X})$. Se realizaron además comparaciones de medias múltiples mediante la prueba de Duncan, lo que permitió identificar con mayor claridad las variables específicas que difieren significativamente entre conglomerados. Para las variables cualitativas se utilizó una prueba de chicuadrado para contrastar la hipótesis de homogeneidad 
en la distribución de fincas entre las categorías de cada variable, según los distintos conglomerados.

\section{RESULTADOS Y DISCUSIÓN}

\section{Estadística descriptiva}

Las categorías más frecuentes dentro de cada variable cualitativa (Cuadro 2) correspondieron a la orientación productiva hacia lechería especializada $(82,9 \%)$, sistemas de confinamiento basados en pastoreo $(72,7 \%)$ y suelos de tipo andisoles $(61,5 \%)$. Según datos disponibles a nivel nacional, el número de lecherías de doble propósito ( $\mathrm{n}=9433$ ) supera el de lecherías especializadas ( $\mathrm{n}=6$ 692) (Camacho-Sandoval 2012), lo cual no se observa en el presente estudio, debido a que la cooperativa que provee los datos integra principalmente a lecherías especializadas. Sin embargo, esta cooperativa representa aproximadamente un $83 \%$ de la leche que se procesa formalmente en el país (Camacho-Sandoval 2012). Por otra parte, si bien hasta cierto punto han proliferado los sistemas semi-estabulados y estabulados, es claro que a nivel poblacional existe todavía una alta dependencia del pastoreo, como lo señalan los datos. Por otra parte, los suelos andisoles tampoco son los más abundantes a nivel nacional, pero son frecuentes a lo largo de las cordilleras volcánicas de Costa Rica, donde tradicionalmente se han establecido las lecherías de altura. Estos suelos son generalmente de color negro, de fertilidad media, profundos y porosos, derivados a partir de cenizas y otros materiales volcánicos, con un alto contenido de materia orgánica y de textura franca o franco-arenosa (Cabalceta-Aguilar 2012).

La mayoría de los hatos se encuentran ubicados dentro de las zonas de vida bosque muy húmedo o bosque húmedo (Holdridge 1987), ya sea dentro de las fajas tropical, premontano o montano. Por esta razón, el nivel de precipitación promedio es alto, cercano a los $3500 \mathrm{~mm}$, y la temperatura es típica de zonas tropicales, cercana a $\operatorname{los} 22^{\circ} \mathrm{C}$, a una altitud promedio ligeramente sobre $800 \mathrm{msnm}$ (Cuadro 3). En términos geográficos la mayoría de estos hatos se localizan en las regiones socioeconómicas Central y Huetar Norte del país, donde se concentran la mayoría de las lecherías en Costa Rica, sobre las faldas de la Cordillera Volcánica Central y la Cordillera de Tilarán. Un pe-
Cuadro 2. Número y porcentaje de hatos lecheros por categoría para las variables de orientación productiva, sistema de confinamiento y tipo de suelo. Costa Rica. 2007.

\begin{tabular}{lcc}
\hline Variables y categorías & Frecuencia & Porcentaje \\
\hline Orientación productiva & 186 & 17,13 \\
Doble propósito & 900 & 82,87 \\
Especializado & & \\
& & \\
Sistema de confinamiento & 789 & 72,65 \\
Pastoreo & 115 & 10,59 \\
Pastoreo y semiestabulación & 28 & 2,58 \\
Pastoreo y estabulación parcial & 144 & 13,26 \\
Semiestabulación & 10 & 0,92 \\
Estabulación & & \\
& & \\
Tipo de suelo & & \\
Ultisoles & 91 & 8,38 \\
Vertisoles & 28 & 2,58 \\
Andisoles & 668 & 61,51 \\
Inceptisoles & 299 & 27,53 \\
\hline
\end{tabular}

${ }^{1}$ Tipo de suelo: solo se considera el orden primario por existir múltiples subórdenes.

queño grupo, principalmente de hatos doble propósito, se ubican hacia la zona de la península de Nicoya.

En promedio, una proporción mayor al $80 \%$ del hato es de razas lecheras especializadas (Cuadro 3). La producción promedio de sólidos de leche por hectárea por semana fue de $32,1 \mathrm{~kg}$, lo que equivale a un aproximado de 257 litros de leche fluida. El promedio de carga animal es de 3,37 vacas en producción/ha, lo que significa que la producción diaria promedio por vaca fue de aproximadamente $10,9 \mathrm{~kg}$ leche. En cuanto a calidad de leche, el conteo bacteriano promedio fue cercano a 34000 UFC y el conteo promedio de células somáticas de aproximadamente $365000 \mathrm{cel} / \mathrm{ml}$ (Cuadro 3).

El hato promedio suministra un equivalente a 4,5 $\mathrm{kg}$ de concentrado y $1,2 \mathrm{~kg}$ de suplementos por vaca por día. Tiene además 2,2 ha de pasto y 0,11 ha de forraje de corte por cada ha en producción, con niveles 
Cuadro 3. Promedio, desviación estándar e intervalo de confianza 95\% para las variables cuantitativas consideradas en el censo $(n=1086)$ para la caracterización de hatos lecheros. Costa Rica 2007.

\begin{tabular}{lllccc}
\hline Variable & Unidades & Promedio & $\begin{array}{c}\text { Desviación } \\
\text { estándar }\end{array}$ & $\begin{array}{c}\text { Límite } \\
\text { inferior } \\
\text { IC- 95\% }\end{array}$ & $\begin{array}{c}\text { Límite } \\
\text { superior }\end{array}$ \\
IC- 95\% \\
\hline Precipitación & mms/año & 3474,0 & 982,9 & 3415,5 & 3532,5 \\
Altitud & $\mathrm{msnm}$ & 816,3 & 739,2 & 772,3 & 860,4 \\
Temperatura & ${ }^{\circ} \mathrm{C}$ & 22,4 & 3,8 & 22,1 & 22,6 \\
Concentrado & $\mathrm{kg} \mathrm{sem} / \mathrm{ha}$ & 105,1 & 93,8 & 99,5 & 110,7 \\
Mano de Obra & peones/ha & 0,15 & 0,18 & 0,14 & 0,16 \\
Carga Animal & vacas/ha & 3,37 & 1,73 & 3,27 & 3,48 \\
Suplementos & $\mathrm{kg} \mathrm{sem} / \mathrm{ha}$ & 27,6 & 131,2 & 19,8 & 35,4 \\
Fertilizantes & $\mathrm{kg} \mathrm{sem} / \mathrm{ha}$ & 7,1 & 10,0 & 6,5 & 7,7 \\
Razas especializadas & \% & 81,7 & 32,6 & 79,8 & 83,6 \\
Pastos & (ha pasto)/(ha) & 2,23 & 1,30 & 2,15 & 2,31 \\
Forraje de corte & (ha corte)/(ha) & 0,11 & 0,11 & 0,11 & 0,12 \\
Administración & $\mathrm{h} / \mathrm{ha}$ & 1,69 & 1,96 & 1,57 & 1,80 \\
Conteo bacterial & $\mathrm{UFC}$ & 33704 & 10720 & 33065 & 34342 \\
Células somáticas & cel/ml & 365013 & 160019 & 355486 & 374541 \\
Sólidos totales & $\mathrm{kg} \mathrm{sem} / \mathrm{ha}$ & 32,1 & 23,5 & 30,7 & 33,5 \\
\hline
\end{tabular}

${ }^{1}$ Intervalo de confianza $95 \%$.

de fertilización equivalentes a $369 \mathrm{~kg} / \mathrm{ha} / \mathrm{año}$, área dedicada a vacas en producción. También posee una relación de 0,15 peones/ha y se le dedica en promedio 1,69 h de tiempo de administración/ha. Cabe notar que alrededor de estos promedios existe para la mayoría de las variables una alta variabilidad, lo que se denota en las altas desviaciones estándares obtenidas (Cuadro 3).

\section{Análisis de factores (AF)}

Se obtuvo un valor conjunto de 0,77 para la Medida de Adecuación Muestral de Kaiser, lo que sugiere que las variables analizadas presentan una alta comunalidad, cercana al rango óptimo para la extracción de factores (Hair et al. 1998). Mediante el análisis de factores se extrajeron dieciocho posibles factores principales, para los que se cuantificaron los autovalores respectivos y la proporción marginal de varianza explicada por cada uno (Figura 1). Únicamente los tres primeros factores principales mostraron autovalores mayores que uno. Estos explicaron respectivamente un $42,6 \%$, $24,2 \%$ y $13,3 \%$ de la varianza presente, en el conjunto original de las dieciocho variables observadas, para un acumulado de $80 \%$ (Figura 1). La proporción de varianza explicada por los factores adicionales (4 hasta 18) fue menor al $6,5 \%$, por lo que se consideran factores triviales (Johnson y Wichern 1998) y su importancia es limitada para efectos descriptivos. En estudios similares generalmente se ha requerido de cuatro o más factores para lograr un acumulado de varianza mayor al 70\% (Serrano-Martínez et al. 2004a, Gaspar et al. 2007, Kirner et al. 2007, Martínez-García et al. 2012). El menor número de factores requerido en el presente estudio probablemente se debe a la estandarización previa de las variables por unidad de área y tiempo, así como a la selección y agregación previa de algunas de las variables utilizadas, tales como los tipos de concentrado y suplementos. La preselección y edición 

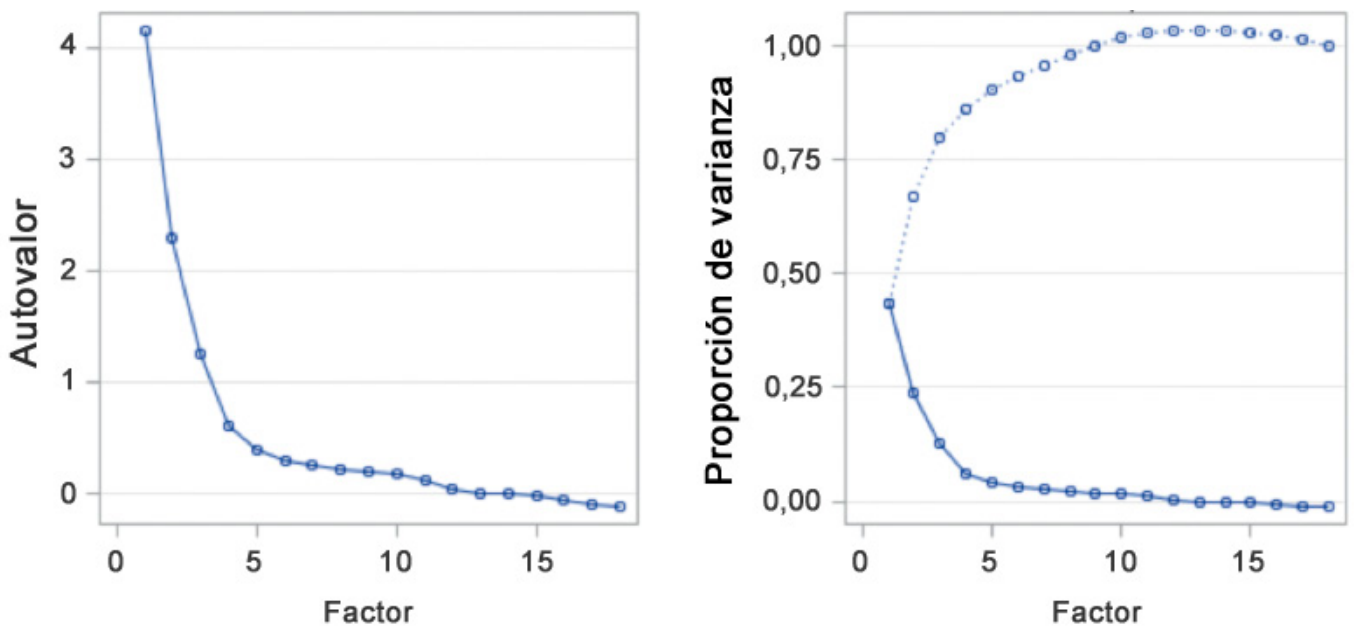

Figura 1. Valor absoluto de autovalores (izquierda, eje y), proporción de varianza marginal (derecha, eje y, línea continua) y varianza acumulada (derecha, eje y, línea discontinua) en función del número de factores seleccionados (eje x) para la caracterización de los hatos lecheros. Costa Rica. 2007.

de las variables es un paso recomendado previo al análisis de factores (Hair et al. 1998).

El análisis de las correlaciones permitió identificar claramente cuáles variables tienen mayor impacto sobre cada uno de los tres factores seleccionados (Cuadro 4). El primer factor presenta asociaciones fuertes y positivas con las variables de producción de sólidos, carga animal, uso de concentrado y uso de fertilizante, asociaciones medias y positivas con forraje, administración, suplementación, orientación productiva, proporción de razas especializadas y mano de obra, y asociaciones bajas con las demás variables. En síntesis, este factor principalmente se relaciona con intensidad de uso de insumos y nivel de producción, por lo que se interpreta que este mide esencialmente el nivel de intensificación de los hatos, que ha sido mencionado en otros estudios como factor determinante en la caracterización de los sistemas de producción agrícolas (Srairi y Lyobi 2003, Serrano Martínez et al. 2004a, Vázquez-Martínez et al. 2009). Este nivel de intensificación en muchos casos va de la mano de variables tales como el uso de concentrado, la carga animal o la producción por hectárea (Srairi y Lyobi 2003, Gaspar et al. 2007, Giorgis et al. 2011, Martínez-García et al. 2012), variables que coinciden con las que se detectaron en el presente estudio.

El segundo factor seleccionado presenta asociaciones fuertes y positivas con las variables de temperatura,
Cuadro 4. Magnitud de las correlaciones lineales entre las variables observadas y los tres factores principales extraídos*. Costa Rica. 2007.

\begin{tabular}{lccc}
\hline Variable & Factor $\mathbf{1}$ & Factor $\mathbf{2}$ & Factor 3 \\
\hline Sólidos totales & $\mathbf{0 , 8 9}$ & $-0,22$ & 0,20 \\
Carga animal & $\mathbf{0 , 8 6}$ & 0,13 & $-0,02$ \\
Concentrado & $\mathbf{0 , 8 4}$ & $-0,19$ & 0,21 \\
Fertilizantes & $\mathbf{0 , 6 2}$ & $-0,16$ & 0,07 \\
Forraje de corte & 0,27 & 0,00 & $-0,02$ \\
Sistema de confinamiento & 0,25 & 0,25 & 0,14 \\
Administración & 0,25 & 0,14 & 0,06 \\
Suplementos & 0,22 & $-0,12$ & $-0,02$ \\
Mano de obra & 0,20 & 0,10 & 0,03 \\
Temperatura & $-0,09$ & $\mathbf{0 , 8 8}$ & $-0,37$ \\
Precipitación & 0,01 & $\mathbf{0 , 6 2}$ & 0,13 \\
Conteo bacterial & $-0,04$ & $\mathbf{0 , 6 2}$ & 0,06 \\
Altitud & 0,10 & $\mathbf{- 0 , 8 7}$ & 0,39 \\
Razas especializadas & 0,29 & $-0,15$ & $\mathbf{0 , 8 0}$ \\
Orientación productiva & 0,32 & $-0,08$ & $\mathbf{0 , 8 0}$ \\
Tipo de suelo & 0,07 & 0,18 & 0,31 \\
Células somáticas & $-0,04$ & 0,20 & 0,22 \\
Pastos & 0,08 & 0,05 & $-0,26$ \\
\hline
\end{tabular}

* Correlaciones mayores a 0,50 se consideran como significativas, mayores a 0,40 son importantes y mayores a 0,30 son de nivel mínimo (Hair et al. 1998). 
precipitación y conteo bacteriano, asociación fuerte y negativa con altitud, y asociaciones medias y positivas con sistema de pastoreo y conteo de células somáticas. Se puede interpretar por lo tanto, que este factor está mayormente ligado a la variable de altitud, la cual está inversamente correlacionada con la temperatura.

El tercer factor presenta asociaciones fuertes y positivas con proporción de raza especializada y orientación productiva; asociaciones medias y positivas con piso altitudinal, uso de concentrado y tipo de suelo; y asociaciones medias y negativas con temperatura y área de pastoreo. Se puede interpretar por lo tanto que este factor se relaciona mayormente con la orientación productiva. Esta y el tipo racial predominante también han resultado ligadas como factor importante en otros estudios enfocados a sistemas ganaderos (SerranoMartínez et al. 2004b, Betancourt et al. 2005). Los hatos lecheros especializados tienden a utilizar razas lecheras puras o sus cruces, mientras que las de doble propósito tienden a utilizar cruces de razas Bos indicus $\times$ Bos taurus. Para obtener una visión más integral del significado de estos factores y su relación con las diferentes tipologías de producción presentes en la población de hatos es necesario combinar los resultados anteriores con el análisis de conglomerados que se describe seguidamente.

\section{Análisis de conglomerados (AC)}

El análisis gráfico del comportamiento de los estadísticos Criterio de Clusterización Cúbica-CCC, Pseudo $\mathrm{F}$ y Pseudo $\mathrm{t}^{2}$ permitió definir el número óptimo de conglomerados (Figura 2). Para una agrupación óptima se debe observar un pico local para CCC, acompañado de un valor alto para el estadístico Pseudo F y bajo para el Pseudo $t^{2}$ (SAS 2008). Esto se obtuvo aproximadamente entre los niveles 4 y 5 de agrupación de conglomerados. Para obtener una descripción más detallada de la población de hatos se seleccionó el nivel de agrupación de cinco conglomerados, con el cual se logró un $\mathrm{R}^{2}$ de 0,72 , lo que ratifica que se logró retener una alta proporción de la varianza original. Niveles de agrupación superiores a cinco no contribuyeron significativamente a mejorar el $\mathrm{R}^{2}$.

Con base en lo anterior, los conglomerados finales se obtuvieron utilizando un nivel de agrupación

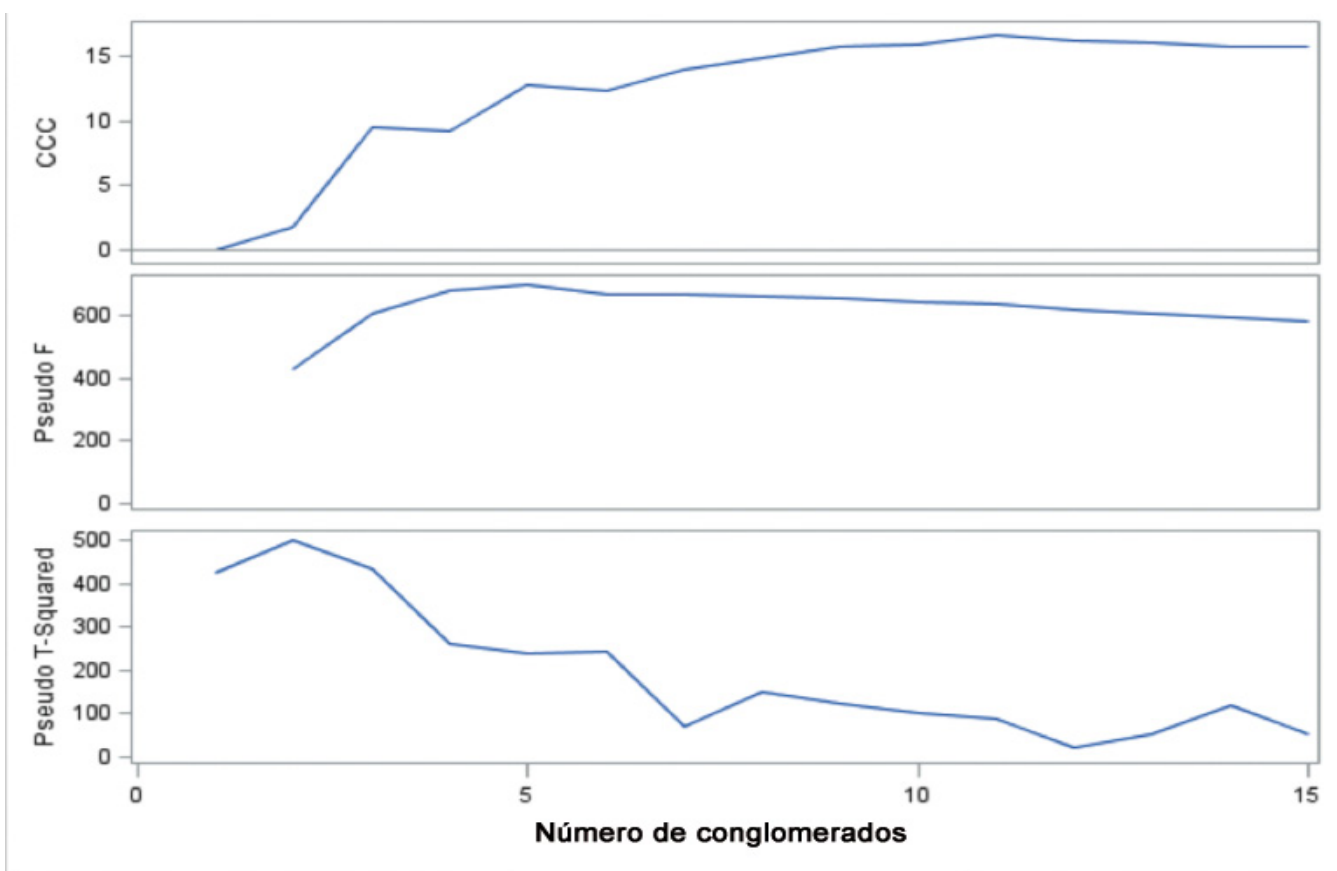

Figura 2. Valores del Criterio de Clusterización Cúbica (CCC), Pseudo F y Pseudo $t^{2}$ en función del número de conglomerados utilizando el método de aglomeración jerárquico de Ward. Costa Rica. 2007. 
de cinco, pero generados mediante el método no jerárquico de agrupación $K$-means. El número de hatos obtenido para los conglomerados del 1 hasta el 5 fue de 374, 274, 167, 189 y 82, respectivamente. Esta estrategia de generación en dos fases tiene por objetivo principal validar la agrupación obtenida por dos métodos distintos, jerárquicos y no jerárquicos. Además, esta estrategia es preferida por sobre el uso exclusivo de métodos jerárquicos, los cuales pueden conducir a óptimos locales (Bernhardt et al. 1996).

En el presente estudio las agrupaciones obtenidas por Ward y K-means, si bien no fueron exactamente iguales, sí fueron muy similares, ya que ambos condujeron a identificar las mismas tipologías de hatos. Dos de los conglomerados resultantes (3 y 5) fueron prácticamente idénticos por ambos métodos, mientras que en los tres restantes existió una pequeña proporción de hatos que fueron ubicados distintamente por ambos métodos, los cuales correspondieron principalmente a hatos que se encuentran en la periferia de los conglomerados, más lejos de los centroides. Esto demuestra que existe consistencia en la agrupación resultante, independientemente del método utilizado. El método $K$-means permitió obtener además la distancia euclideana entre los centroides de los cinco conglomerados, siendo el 1 y 3 los más cercanos entre sí (1,47 unidades euclideanas) mientras que los conglomerados 2 y 5 fueron los más lejanos (3,34 unidades euclideanas).

La proyección de las variables (Figura 3, a la izquierda) y de los hatos (Figura 3, a la derecha) sobre el plano formado por los factores seleccionados (1 vs. 2 y 1 vs. 3) permitió lograr una interpretación conjunta de la estructura de los factores y su relación con el agrupamiento obtenido en el análisis de conglomerados.

El plano formado por los factores 1 vs. 2 (Figura 3 , superior) fue el más importante, ya que acumula un $66,7 \%$ de la varianza total. En este plano factorial los vectores representan variables que se proyectan hacia la derecha (o izquierda) en función de las correlaciones positivas (o negativas) con el primer factor principal (Cuadro 4). Asimismo, la longitud de los vectores (variables) está en función de la magnitud de las correlaciones con el factor respectivo. De igual manera, la posición de los hatos dentro del plano factorial está en función de su afinidad o no con las variables que se proyectan en la misma o distinta dirección. Por ejemplo, los hatos que se ubican hacia la derecha son los que se caracterizan por tener mayores índices para las variables que se orientan en esa dirección, tales como vacas por hectárea, producción de sólidos, uso de concentrados y de fertilizantes. Este factor discrimina, principalmente a los conglomerados 3 y 5 (más intensivos, a la derecha), de los conglomerados 1, 2 y 4 (menos intensivos, a la izquierda). En este mismo plano factorial, pero en sentido vertical, las variables que se proyectan hacia arriba (o abajo) son aquellas que presentaron correlaciones positivas (o negativas) con el segundo factor principal (Cuadro 4). Por lo tanto, los hatos ubicados en la parte superior, principalmente pertenecientes a los conglomerados 1 , 3 y 4 se caracterizaron por estar en zonas bajas, con alta temperatura, alta precipitación y mayores conteos bacteriales. Por el contrario, los hatos ubicados en el extremo inferior de este eje, principalmente pertenecientes a los conglomerados 2 y 5 , serían hatos ubicados a mayor altitud, con menor temperatura, precipitación y conteos bacteriales. En síntesis, este plano factorial subdivide los hatos en cuatro tipos: intensivos de bajura (arriba a la derecha), de altura (abajo a la derecha), extensivos de bajura (arriba a la izquierda) y de altura (abajo a la derecha).

El plano formado por los factores 1 vs. 3 (Figura 3 , inferior) permite discriminar con mayor claridad el conglomerado 4. En este plano, las variables que se proyectan hacia arriba (o abajo) son aquellas que presentaron correlaciones positivas (o negativas) con el tercer factor principal (Cuadro 4). Por lo tanto, los hatos ubicados en la parte inferior de este eje, principalmente pertenecientes al conglomerado 4 , son los que tienen una orientación productiva hacia el doble propósito, ubicados en zonas bajas con alta temperatura, mayor área de pastoreo, menor proporción de razas especializadas y suelos menos fértiles. Por el contrario, los hatos ubicados en el extremo superior de este eje, pertenecientes a los demás conglomerados, están conformados principalmente por lecherías especializadas con distintos niveles de intensificación según su ubicación a lo largo del factor 1 (eje x), según se describió para el plano anterior.

En otros estudios multivariados realizados con hatos lecheros, se han encontrado patrones similares de distribución (Smith et al. 2002, Giorgis et al. 2011). Variables como el tamaño y productividad de los hatos (Giorgis et al. 2011), la carga animal y el 

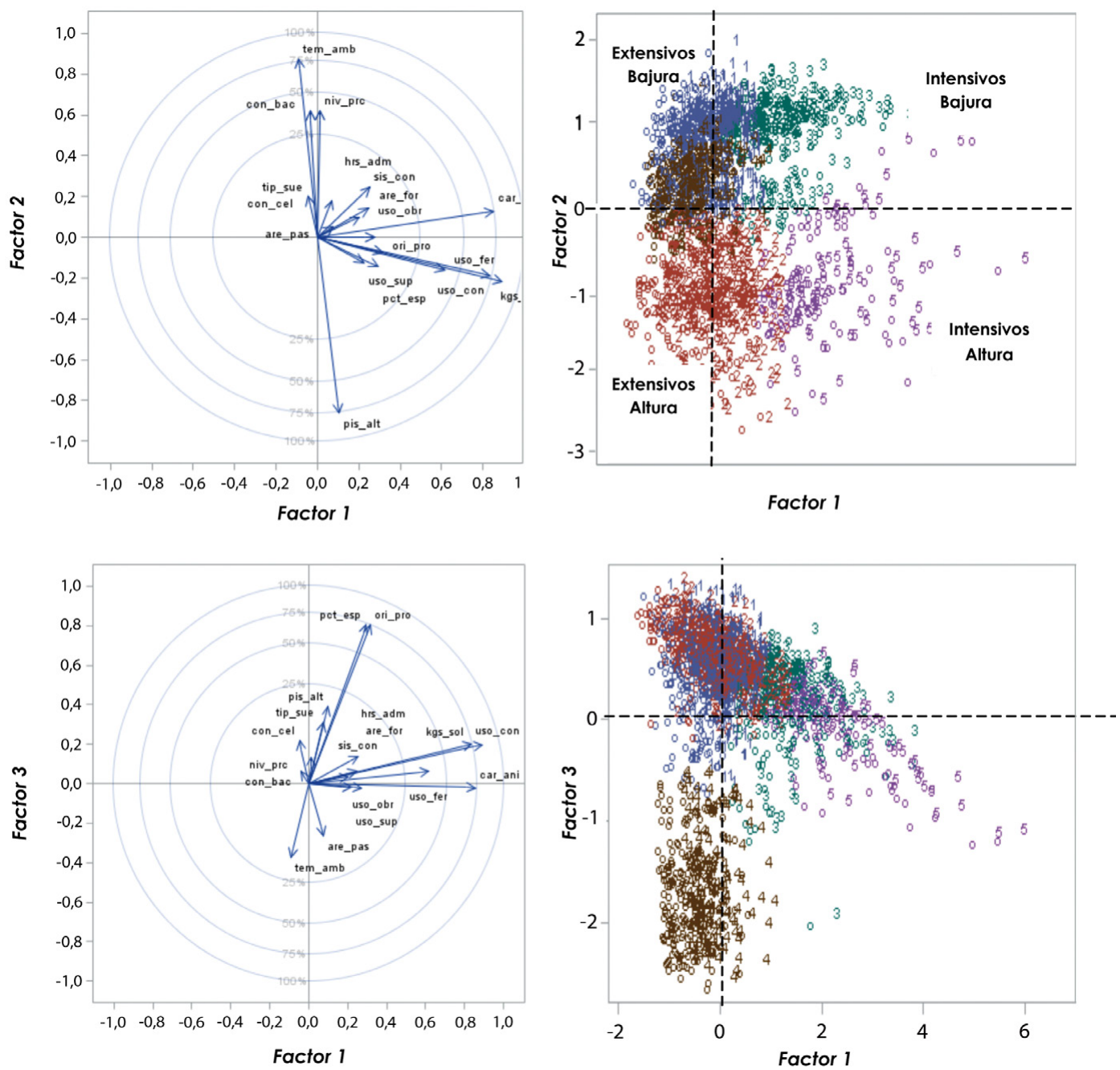

Figura 3. Sobreposición de los vectores de variables (a la izquierda, niv_prc: precipitación, tem_amb: temperatura, pis_alt: altitud, are_pas: area pasto, are_for: área forraje, uso_fer: fertilizante, uso_obr: mano de obra, hrs_adm: administración, uso_con: concentrado, uso_sup: suplementos, car_ani: carga animal, pct_esp: \% ganado especializado, con_cel: células somáticas, con_bac: conteo bacterial, kgs_sol: sólidos totales) y conglomerados (a la derecha) en el plano formado por los factores principales $1 \mathrm{vs} .2$ (superior) y $1 \mathrm{vs} .3$ (inferior), en la caracterización de hatos lecheros. Costa Rica. 2007.

porcentaje de pastos mejorados (Smith et al. 2002) o la proporción de concentrados en la ración y el costo de producción (Srairi y Lyobi 2003) están entre las que más influencian el primer factor y por ende, las agrupaciones obtenidas posteriormente.

\section{Comparación de conglomerados según variables observadas}

Se comparó la distribución de hatos en distintas categorías por conglomerado para cada una de las 
variables cualitativas: orientación productiva, sistema de confinamiento y tipo de suelo (Figura 4). De acuerdo con la prueba de chi-cuadrado, en todos los casos se comprobó que las distribuciones de hatos por categoría fueron significativamente heterogéneas entre conglomerados $(\mathrm{P}<0,001)$.

En cuanto a orientación productiva el conglomerado 4 está formado, casi exclusivamente, por fincas
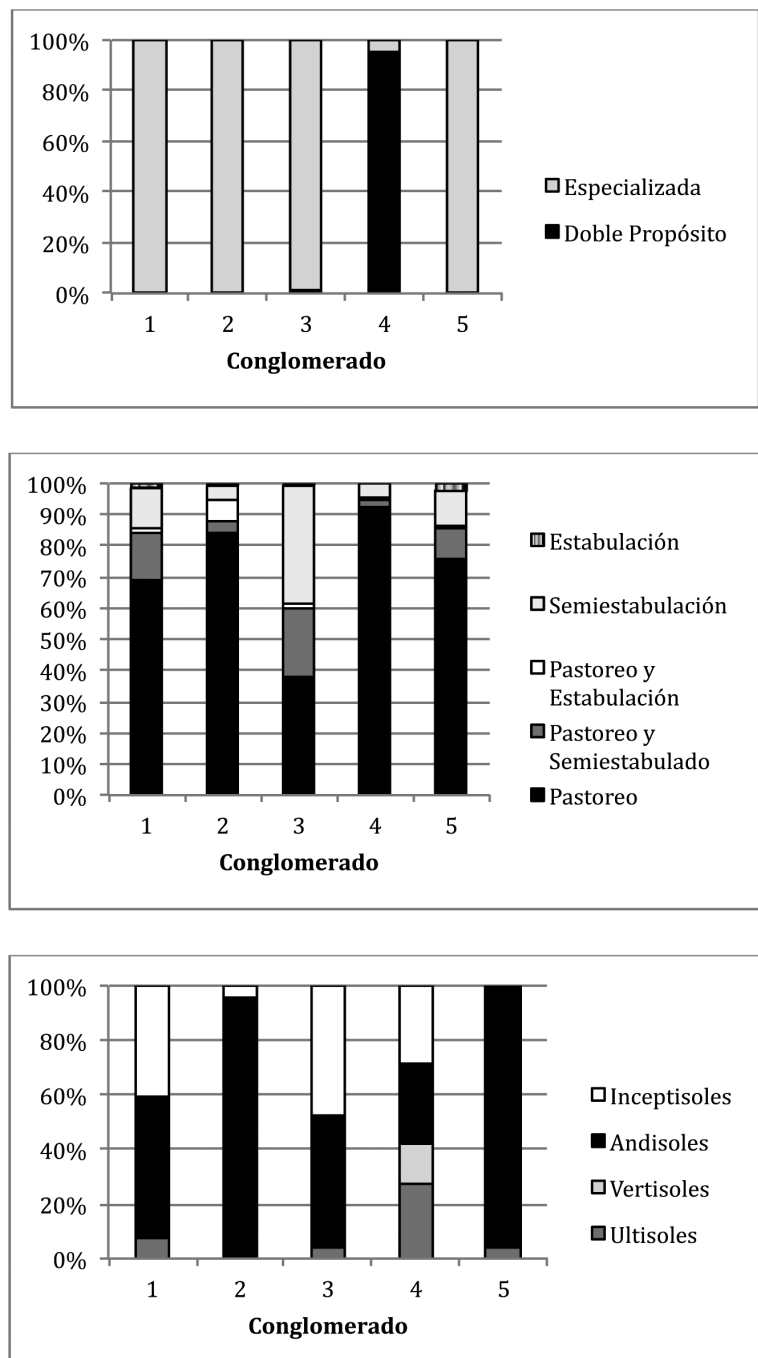

Figura 4. Distribución porcentual (eje y) de categorías (sectores dentro de columnas) por conglomerado (eje x) para las variables de orientación productiva (superior), sistema de confinamiento (intermedio) y tipo de suelo (inferior), en la caracterización de hatos lecheros. Costa Rica. 2007. de doble propósito, mientras que los demás reúnen casi exclusivamente fincas de lechería especializada. El sistema de doble propósito posee características muy particulares que lo identifican como un grupo aislado de los demás, lo que se ratificó en el presente estudio, ya que fue el de mayor distancia euclideana promedio con respecto a los demás. La segregación de conglomerados por orientación productiva se ha observado también en otros estudios (Betancourt et al. 2005, Serrano-Martínez et al. 2004b).

En cuanto al sistema de confinamiento se observa como en los conglomerados 2 y 4 hay marcada predominancia del pastoreo sobre los otros sistemas, mientras que en los conglomerados 1 y 5 , si bien predomina el pastoreo, se observó una proporción importante de semiestabulados y sistemas combinados de semiestabulado y pastoreo. Se observa también como en el conglomerado 3 hay una distribución más equitativa de los distintos tipos de sistemas. El grado de confinamiento se ha reportado en otro estudio como una variable importante para la discriminación de conglomerados (Smith et al. 2002), asociada positivamente con variables tales como producción por vaca o productividad de la mano de obra.

En cuanto al tipo de suelo se observa que los hatos de los conglomerados 2 y 5 están establecidos casi exclusivamente sobre suelos andisoles, mientras que en el 1 y 3 hay distribución equitativa de andisoles e inceptisoles. Los suelos andisoles cubren aproximadamente un $14 \%$ del territorio. Son suelos de origen volcánico muy abundantes en las faldas de la Cordillera Volcánica Central, siendo muy utilizados para la ganadería de leche en zonas altas y para la agricultura en general (Bertsch et al. 2000). Los inceptisoles son los suelos más abundantes en Costa Rica, cubriendo aproximadamente un $39 \%$ del territorio, siendo también ampliamente utilizados para la agricultura y la ganadería (Bertsch et al. 2000).

En el conglomerado 4, además de los 2 tipos anteriores de suelo, hay también presencia significativa de suelos ultisoles y vertisoles. Los ultisoles corresponden a los suelos más viejos y meteorizados de Costa Rica, siendo de integración marginal para la actividad agrícola (Bertsch et al. 2000). Los vertisoles por su parte, se encuentran en las zonas planas y depresionales del Pacífico Seco de Costa Rica. Aunque son suelos fértiles, su alto contenido de arcilla y propensión a inundarse los hace poco adecuados para el desarrollo de pasturas y la ganadería en general (Bertsch et al. 2000). 
Los resultados de los ANOVA univariados también indicaron diferencias significativas entre conglomerados para todas las variables de tipo cuantitativo. Para la variable $\mathrm{kg}$ de sólidos, la más representativa del nivel de producción de los hatos, se detectaron diferencias significativas entre todos los conglomerados, siendo mayor la media de los conglomerados 5 y 3 , sobre los 2, 1 y 4 (Figura 5). Esta variable tuvo además un alto poder discriminatorio, ya que su $\mathrm{R}^{2}$ fue de 0,70 .

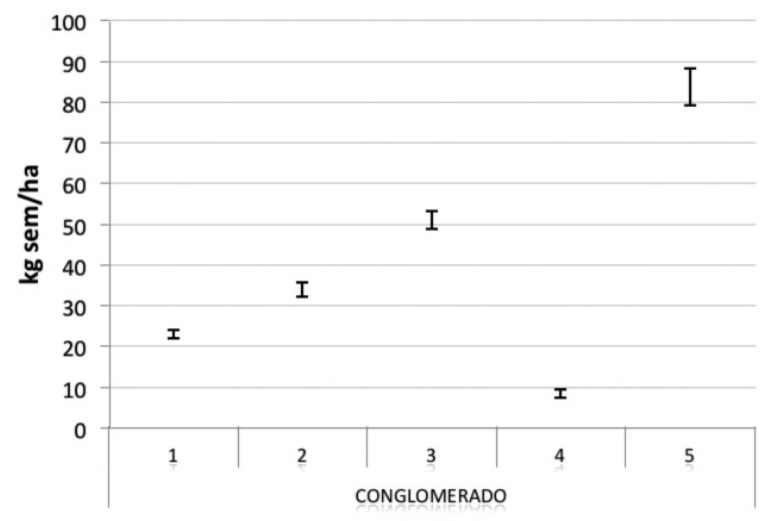

Figura 5. Promedios e intervalo de confianza $95 \%$ de la variable Producción de Sólidos Totales ( $\mathrm{kg}$ sem/ ha) en función de los conglomerado en la caracterización de hatos lecheros. Costa Rica. 2007.

Otras variables cuantitativas de importante poder discriminatorio $\left(\mathrm{R}^{2}>0,30\right)$ fueron el porcentaje de raza especializada, la altitud, el uso de concentrado, la temperatura, la carga animal y el nivel de precipitación (Figura 6). En cuanto a porcentaje de raza especializada se observó la marcada diferencia del conglomerado 4, donde la proporción de animales especializados es mínima, lo cual se debe a que son mayormente de doble propósito con ganado mestizo (Figura 5). En cuanto a la variable de altitud, se diferencian claramente los conglomerados 2 y 5, sobre los $1500 \mathrm{msnm}$, contra los demás, ubicados por debajo de los $500 \mathrm{msnm}$. El patrón inverso se observó en temperatura, ya que los conglomerados 1, 3 y 4, de zonas más bajas, son los que presentaron las mayores temperaturas, por arriba de los $24^{\circ} \mathrm{C}$, mientras que los otros dos de zonas más altas, presentaron temperaturas promedio por debajo de los $19^{\circ} \mathrm{C}$. En cuanto a precipitación se observó que las mayores están en los conglomerados 3 y 1 , cerca de los $4000 \mathrm{~mm}$ anuales en promedio, seguido por el 4, cerca de $3300 \mathrm{~mm}$ y el 3 y 5 , por debajo de los $2800 \mathrm{~mm}$.

Por otra parte en uso de concentrado, se observó un patrón similar al de producción de sólidos, con mayores medias para el conglomerado 5, seguido por los conglomerados 3, 2, 1 y 4. Esta variable es la que presenta una asociación más fuerte con producción de sólidos, existiendo una correlación lineal entre ambas de 0,86 (P<0,0001). El mismo patrón se repitió aproximadamente para la variable de carga animal, aunque en este caso no hay diferencia significativa entre las medias de los conglomerados 1 y 2. La correlación lineal con producción de sólidos es en este caso de $0,76(\mathrm{P}<0,0001)$.

La producción expresada por vaca o por área, es una variable que ha sido reportada en varios estudios como una de las más determinantes en la agrupación de hatos lecheros mediante análisis de conglomerados (Smith et al. 2002, Srairi y Lyobi, 2003, Giorgis et al. 2011, Martínez-García et al. 2012). Lo mismo sucede con la carga animal (Smith et al. 2002, Giorgis et al. 2011, Martínez-García et al. 2012) y el uso de concentrado (Smith et al. 2002, Srairi y Lyobi 2003, Giorgis et al. 2011).

Varios estudios han aplicado el análisis de conglomerados para agrupar explotaciones lecheras (Solano et al. 2000, Smith et al. 2002, Srairi y Lyobi 2003, Giorgis et al. 2011, Gelasakis et al. 2012, MartínezGarcía et al. 2012). En estos estudios el número de agrupaciones obtenidas varió entre 3 y 5 , similar al obtenido en el presente trabajo. Las tipologías obtenidas no son directamente comparables ya que, aunque las metodologías de agrupación coinciden, el número y tipo de variables utilizadas difieren considerablemente. A pesar de la heterogeneidad en las variables específicas utilizadas, casi todos los estudios combinan variables de tipo estructural, con índices de productividad técnico-económica, y variables relacionadas con manejo nutricional, genético, reproductivo o sanitario (Smith et al. 2002, Srairi y Lyobi 2003, Giorgis et al. 2011, Martínez-García et al. 2012). En algunos casos se analizan además ciertas características y actitudes de los propietarios de los hatos (Solano et al. 2000, Gelasakis et al. 2012, Martínez-García et al. 2012).

El tamaño de los conglomerados obtenidos en estos estudios es variable, siendo que en algunos casos uno solo incluye hasta el $70 \%$ de los hatos (Smith et 


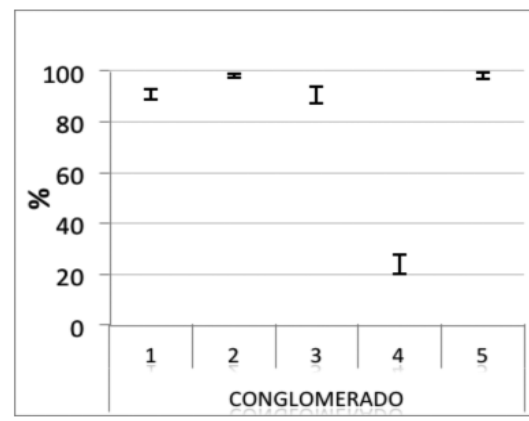

(a) \% de Ganado especializado $\left(R^{2}=0,68\right)$

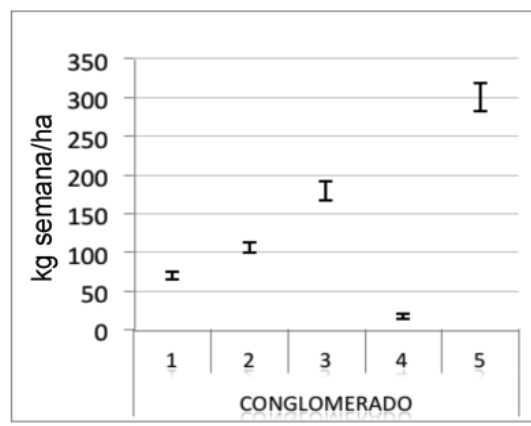

(d) Uso concentrado $\left(\mathrm{R}^{2}=0,62\right)$

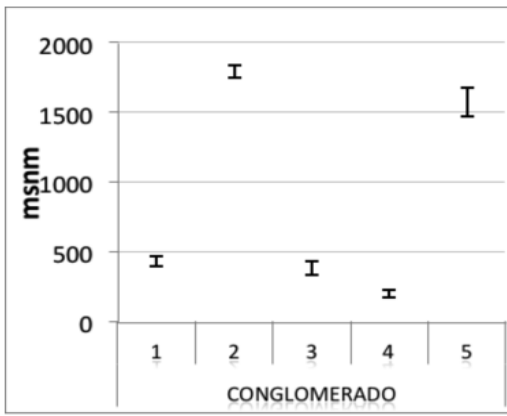

(b) Piso altitudinal $\left(R^{2}=0,79\right)$

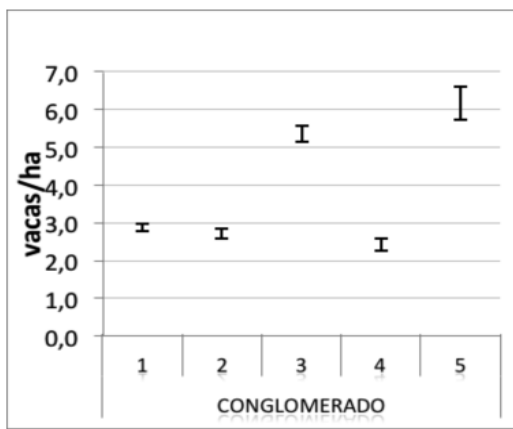

(e) Carga animal $\left(R^{2}=0,52\right)$

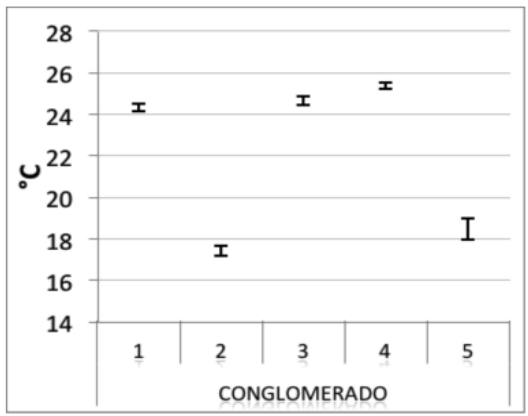

(c) Temperatura ambiental $\left(R^{2}=0,78\right)$

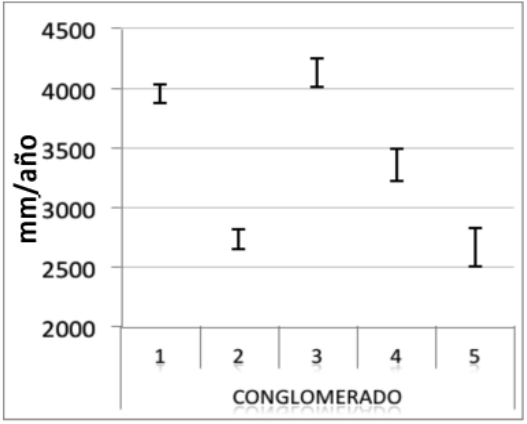

(f) Nivel de precipitación $\left(R^{2}=0,35\right)$

Figura 6. Promedio e intervalo de confianza 95\% de variables cuantitativas con mayor poder discriminatorio en función de los conglomerados en la caracterización de hatos lecheros. Costa Rica. 2007.

al. 2002) mientras que otros solo contienen unas pocas unidades, correspondientes a casos atípicos dentro de la población estudiada. Otro aspecto coincidente entre estudios es que las variables estructurales y los índices técnico-económicos generalmente tienen una gran influencia sobre las agrupaciones obtenidas (Smith et al. 2002, Srairi y Lyobi 2003, Giorgis et al. 2011, Martínez-García et al. 2012).

Las demás variables incluidas en el presente estudio presentaron diferencias significativas entre conglomerados, pero su poder discriminatorio fue menor, con valores de $\mathrm{R}^{2}$ menores a 0,30 (Cuadro 5). Las medias por conglomerado para las variables de uso de fertilizante, uso de mano de obra, uso de suplementos, administración y área dedicada a forraje presentaron una tendencia a mayores medias para el 5 y 3 , pero las diferencias entre los demás conglomerados no fueron marcadas. La variable de área dedicada a pastoreo discriminó al 4 de los demás, lo que confirma que las fincas de doble propósito tienden a ser más extensivas en términos de área dedicada a pastoreo.

El patrón de agrupación para conteo bacteriano coincide con el observado para temperatura, con valores más altos en los conglomerados 7, 3 y 4, y menores en los 2 y 5 . Estos promedios pueden considerarse aceptables si se considera que las industrias generalmente requieren conteos inferiores a las $100000 \mathrm{UFC} / \mathrm{ml}$ o en casos más rigurosos $50000 \mathrm{UFC} / \mathrm{ml}$ (CANILEC 2011).

En cuanto a células somáticas se observa de nuevo que los conglomerados 1 y 3 presentaron mayores medias, sin embargo, en este caso la media del conglomerado 4 es la menor. Esto podría deberse a que en hatos de doble propósito la práctica usual es dejar que los terneros mamen la leche residual del ordeño, lo que podría tener un efecto beneficioso en el control de mastitis. Cabe señalar que un conteo de células somáticas 
Cuadro 5. Promedio, error estándar y jerarquización Duncan de variables cuantitativas de menor poder discriminatorio en función de los conglomerado. Costa Rica. 2007.

\begin{tabular}{|c|c|c|c|c|c|c|c|}
\hline Conglomerado & Promedio & E. $\mathbf{E}^{1}$ & Duncan $^{2}$ & Conglomerado & Promedio & E. $\mathbf{E}^{1}$ & Duncan $^{2}$ \\
\hline \multicolumn{4}{|c|}{ Fertilizante $R^{2}=0,28$} & \multicolumn{4}{|c|}{ Mano de obra $R^{2}=0,03$} \\
\hline 5 & 19,99 & 2,01 & $\mathrm{a}$ & 5 & 0,20 & 0,02 & $\mathrm{a}$ \\
\hline 3 & 13,93 & 0,94 & $\mathrm{~b}$ & 3 & 0,20 & 0,02 & a \\
\hline 2 & 7,06 & 0,46 & $\mathrm{c}$ & 1 & 0,14 & 0,01 & $\mathrm{~b}$ \\
\hline 1 & 4,15 & 0,27 & d & 2 & 0,13 & 0,01 & $\mathrm{~b}$ \\
\hline 4 & 1,32 & 0,17 & e & 4 & 0,12 & 0,02 & $\mathrm{~b}$ \\
\hline \multicolumn{4}{|l|}{ Pasto $R^{2}=0,05$} & \multicolumn{3}{|c|}{ Bacterias $\mathbf{R}^{2}=\mathbf{0 , 2 3}$} & \\
\hline 4 & 2,75 & 0,11 & a & 3 & 38230 & 637 & $\mathrm{a}$ \\
\hline 5 & 2,44 & 0,20 & $\mathrm{~b}$ & 1 & 38132 & 490 & $\mathrm{a}$ \\
\hline 3 & 2,36 & 0,10 & $\mathrm{bc}$ & 4 & 34319 & 827 & $\mathrm{~b}$ \\
\hline 1 & 2,12 & 0,06 & $\mathrm{~cd}$ & 2 & 26874 & 537 & $\mathrm{c}$ \\
\hline 2 & 1,89 & 0,06 & $\mathrm{~d}$ & 5 & 25692 & 881 & $\mathrm{c}$ \\
\hline \multicolumn{4}{|l|}{ Forraje $R^{2}=0,05$} & \multicolumn{3}{|c|}{ Suplementos $R^{2}=0,07$} & \\
\hline 5 & 0,19 & 0,03 & a & 5 & 146,55 & 40,38 & a \\
\hline 3 & 0,14 & 0,01 & $\mathrm{~b}$ & 3 & 26,28 & 9,79 & $\mathrm{~b}$ \\
\hline 1 & 0,10 & 0,00 & $\mathrm{c}$ & 2 & 25,61 & 5,04 & $\mathrm{~b}$ \\
\hline 2 & 0,10 & 0,00 & $\mathrm{c}$ & 1 & 13,07 & 3,56 & $\mathrm{~b}$ \\
\hline 4 & 0,10 & 0,01 & $\mathrm{c}$ & 4 & 8,84 & 2,41 & $\mathrm{~b}$ \\
\hline \multicolumn{4}{|c|}{ Administración $R^{2}=0,04$} & \multicolumn{3}{|c|}{ Células $R^{2}=0,04$} & \\
\hline 3 & 2,53 & 0,17 & $\mathrm{a}$ & 1 & 403106 & 8662 & a \\
\hline 5 & 2,25 & 0,29 & $\mathrm{a}$ & 3 & 376569 & 10740 & $a b$ \\
\hline 1 & 1,62 & 0,09 & $\mathrm{~b}$ & 2 & 347974 & 9821 & $\mathrm{bc}$ \\
\hline 2 & 1,44 & 0,12 & $\mathrm{bc}$ & 5 & 343393 & 19331 & $\mathrm{c}$ \\
\hline 4 & 1,19 & 0,11 & $\mathrm{c}$ & 4 & 313507 & 9545 & $\mathrm{c}$ \\
\hline
\end{tabular}

${ }^{1}$ Error Estándar

${ }^{2}$ Medias con literales distintas difieren estadísticamente $(\mathrm{P}<0,05)$.

por encima de $200000 \mathrm{cel} / \mathrm{ml}$ es indicativo de presencia de mastitis subclínica en el hato (Wattiaux 2005). Los conteos entre 200 y $400000 \mathrm{cel} / \mathrm{ml}$ son frecuentes en hatos con buenas prácticas de manejo general, pero que requieren de un programa eficaz de control de mastitis subclínica (Wattiaux 2005). Este parece ser el caso de la mayoría de los hatos incluidos en el presente estudio.

\section{Tipologías de hatos}

Con base en los resultados anteriores es posible construir un perfil o tipología para los hatos pertenecientes a los cinco conglomerados, la cual se resume a continuación.
Conglomerado 1. Lecherías especializadas extensivas de bajura. Este es el más grande e integra el $34,4 \%$ de los hatos. Los hatos de este conglomerado son mayormente lecherías especializadas de bajura pero extensivas, ubicadas mayormente en suelos de tipo andisol o inceptisol en zonas medias y bajas de San Carlos, Upala y Sarapiquí, donde las temperaturas son altas y las precipitaciones cercanas a los 4000 mms anuales. En este predominó el pastoreo, aunque hay una proporción significativa de sistemas semiestabulados (completos o asociados con pastoreo). Estos hatos producen cerca de una cuarta parte de sólidos por hectárea en comparación con lecherías intensivas de altura (conglomerado 5) y menos de la mitad que 
las lecherías intensivas de bajura (conglomerado 3). Utilizan menos concentrado y suplementos por hectárea, producto de una menor carga animal, lo que a su vez podría asociarse al menor uso de fertilizantes y posiblemente al uso de forrajes de menor productividad y calidad. Estos hatos son los que presentan mayores conteos bacterianos y de células somáticas, lo que puede estar asociado en parte a la alta humedad y temperatura, ligado posiblemente a sistemas de enfriamiento menos eficientes y mayores distancias a los centros de acopio. La diferencia entre el conglomerado 1 y 3 radica en la eficiencia de uso del recurso tierra, ya que las producciones diarias promedio por vaca fueron similares (8,1 vs. $9,5 \mathrm{~kg}$, respectivamente).

Conglomerado 2. Lecherías especializadas semiintensivas de altura. Este conglomerado integra un $25,2 \%$ de los hatos, corresponde a lecherías semi-intensivas con ganado especializado, ubicadas en suelos de tipo andisol en las zonas más altas de la Cordillera Volcánica Central, con menor temperatura y precipitaciones cercanas a los $2700 \mathrm{~mm}$ anuales. Estos hatos producen menos de la mitad de sólidos por hectárea en comparación con las lecherías intensivas de altura (conglomerado 5), pero utilizan menos concentrado, suplementos y fertilizantes; lo que consecuentemente implica una menor carga animal. Al calcular la producción de sólidos por vaca por semana, se observa que la diferencia entre los conglomerados 2 y 5 es mucho menor, siendo de 12,5 y $13,6 \mathrm{~kg}$, respectivamente. Esto significa que la diferencia entre estos radica en la eficiencia de uso del recurso tierra y no tanto en la eficiencia por vaca. Los hatos del conglomerado 5 hacen un mayor uso de forrajes de corte y fertilizan más intensivamente que los del conglomerado 3. Por otra parte, los conteos bacterianos en los hatos de este conglomerado son bajos y los de células somáticas son de nivel intermedio.

Conglomerado 3. Lecherías especializadas intensivas de bajura. Integra un $15,4 \%$ de los hatos y corresponde a lecherías intensivas con ganado especializado, ubicadas en suelos de tipo andisol o inceptisol en las zonas medias y bajas de San Carlos, Tilarán, Sarapiquí, donde las temperaturas son altas y las precipitaciones superiores a los $4000 \mathrm{~mm}$ anuales. En este conglomerado hay una alta incidencia de sistemas semiestabulados (completos o combinados con pastoreo), los cuales predominan sobre el pastoreo continuo. Aunque la carga animal es similar a las lecherías intensivas de altura (conglomerado 5), su producción de sólidos por hectárea solo llega al 60\% del logrado en altura. Al calcular la producción de sólidos por vaca por semana, se observa una diferencia marcada entre el conglomerado 3 y 5 (9,5 vs. 13,6 kg, respectivamente). Esto implica que para este caso, las diferencias observadas en producción por hectárea están ligadas mayormente a las diferencias en producción por vaca. Dado que en ambos conglomerados hay una alta proporción de ganado especializado, un factor que podría estar asociado con esta marcada diferencia es el menor rendimiento reproductivo del ganado especializado en zonas de bajura. Esta variable no se cuantificó en el presente estudio.

Conglomerado 4. Lecherías de Doble Propósito de bajura. Integra el $17,4 \%$ de los hatos y es el que más difiere por estar conformado casi exclusivamente por hatos de doble propósito, con ganado no especializado producto de cruces Bos indicus $\times$ Bos taurus. La producción de sólidos por hectárea es la menor, cerca de una décima parte de lo producido por hatos del conglomerado 5. Estos hatos se ubican principalmente en las zonas bajas y húmedas de la región norte (San Carlos y Sarapiquí) y otros en la península de Nicoya. Estos hatos se establecen en muchos casos sobre suelos con problemas estructurales (vertisoles) o de baja fertilidad (ultisoles), con temperatura promedio superior a $25^{\circ} \mathrm{C}$ y precipitaciones cercanas a los $3300 \mathrm{mms}$ anuales. Hacen menor uso de concentrado, suplementos, fertilizantes, mano de obra y administración. Presentan una menor carga animal y dependen en mayor grado del pastoreo. En términos de calidad de leche, estos hatos tienden a presentar conteos bacterianos intermedios y menores conteos de células somáticas.

Conglomerado 5. Lecherías especializadas intensivas de altura. Integra el 7,6\% de los hatos y corresponden a lecherías intensivas altamente tecnificadas, generalmente establecidas sobre los $1600 \mathrm{msnm}$, con ganado puro especializado y con la mayor producción de sólidos por hectárea. Estas fincas se ubican principalmente en las faldas de los volcanes, en suelos de tipo andisol, en lugares como Zarcero, Varablanca, Coronado y Pacayas, con precipitación cercana a los $2600 \mathrm{mms}$ anuales, y temperaturas promedio por debajo de $\operatorname{los} 19^{\circ} \mathrm{C}$. Hacen un alto uso de concentrado, suplementos, fertilizantes, mano de obra y administración. Dentro de este conglomerado hay una proporción significativa de sistemas semiestabulados o combina- 
ciones de pastoreo con semiestabulados; asimismo presentan la carga animal más alta. En cuanto a calidad de leche son hatos con bajos conteos bacterianos y de células somáticas.

Tradicionalmente se ha dividido a los sistemas de producción de leche en tres grupos: la lechería especializada de altura, de bajura y sistemas de doble propósito (Vargas-Leitón 2000, González-Echeverría 2012). En términos generales, los resultados obtenidos en el presente estudio mediante los análisis multivariados respaldan esa clasificación, pero señalan también la necesidad de una subdivisión adicional entre los sistemas de lechería especializada, tanto en la altura como en bajura, que refleje principalmente el grado de intensificación de estos sistemas. Las variables que mayormente determinan este nivel de intensificación son la producción por hectárea, el uso de concentrado, la carga animal y el uso de fertilizantes.

Las tipologías obtenidas pueden servir de base para dirigir políticas de extensión por parte de la empresa involucrada. Se pueden identificar las principales limitaciones que enfrentan los sistemas de producción pertenecientes a cada tipología. Así por ejemplo, en lecherías especializadas extensivas de bajura (conglomerado 1) una de las principales limitantes es la falta de pasturas productivas adaptadas a suelos marginales del trópico. En lecherías especializadas semi-intensivas de altura (conglomerado 2) una de las limitantes parece ser el menor uso de suplementos alimenticios y forrajes. En lecherías especializadas intensivas de bajura (conglomerado 3) se debe cuestionar el uso que se hace de razas lecheras Bos taurus, ya que las circunstancias ambientales les impiden alcanzar su potencial productivo, mientras que los costos por alimentación y manejo reproductivo pueden ser iguales o mayores que en sistemas especializados de altura. En lecherías de doble propósito de bajura (conglomerado 4) una de las principales limitantes radica en el uso de tipos raciales de bajo potencial productivo y la ausencia de una estrategia de mejoramiento genético. Por último, en las lecherías especializadas intensivas de altura (conglomerado 5) la mayor limitante es posiblemente el costo de producción, por lo que las soluciones deben ir orientadas a buscar fuentes alimenticias de alta calidad pero de menor costo que el concentrado.

En relación a lo anterior, se pretende que los resultados obtenidos en el presente estudio sean utilizados como punto de partida para un análisis más exhaustivo de los factores que causan variabilidad en los niveles de eficiencia de hatos lecheros que presentan tipologías similares.

\section{LITERATURA CITADA}

Avilez, JP; Escobar, P; Von Fabeck, G; Villagran, K; García, F; Matamoros, R; García Martínez, A. 2010. Caracterización productiva de explotaciones lecheras empleando metodología de análisis multivariado. Universidad de Zulia 20:74-80.

Bernhardt, KJ; Allen, JC; Helmers, GA. 1996. Using cluster analysis to classify farms for conventional/alternative systems research. Review of Agricultural Economics 18:599-611.

Bertsch, F; Alvarado, A; Henríquez, C; Mata, R. 2000. Properties, geographic, distribution, and management of major soil orders of Costa Rica. In Hall, Ch. A. S. ed. Quantifying sustainable development: the future of tropical economies. San Diego, California, USA, Academic Press. p. 265-294.

Betancourt, K; Ibrahim, M; Villanueva, C; Vargas, B. 2005. Farm management characterization of dairy production systems from the Bulbul river basin, Matiguás, Matagalpa, Nicaragua. Livestock Research for Rural Development 17(7) (en línea). Consultado 1 enero 2013. Disponible en http://www.lrrd.org/ lrrd17/7/beta17080.htm

Cabalceta-Aguilar, G. 2012. Principales tipos de suelos dedicados a la producción de forrajes en Costa Rica. In Memorias Congreso Nacional Lechero 2012. San Carlos, Costa Rica (en línea). Consultado 1 enero 2013. Disponible en http://www.proleche.com/2012.aspx

Camacho-Sandoval, A. 2012. Costa Rica supera las 16000 fincas lecheras. El Financiero. 05 de febrero 2012 (en línea). Consultado 1 enero 2013. Disponible en http:// wvw.elfinancierocr.com/ef_archivo/2012/febrero/05/ negocios3059112.html

CANILEC (Cámara Nacional de Industriales de la Leche). 2011. El libro blanco de la leche y los productos lácteos. México D.F., México. 156 p.

Daniel, WW. 2002. Bioestadística. Base para el análisis de las ciencias de la salud. 4 ed. Traduc. por F. León Hernández. México D.F., México, Edit. Limusa. 878 p.

Gaspar, P; Mesías, FJ; Escribano, AE; Rodríguez, A; Pulido, F. 2007. Economic and management characterization 
of dehesa farms: implications for their sustainability. Agroforestry Systems 71:151-162

Gelasakis, AI; Valergakis, GE; Arsenos, G; Banos, G. 2012. Description and typology of intensive Chios dairy sheep farms in Greece. Journal of Dairy Science 95:3070-3079.

Giorgis, A; Perea-Muñoz, JM; García-Martínez, A; GómezCastro, AG; Angón-Sánchez de Pedro, E; Larrea, A. 2011. Caracterización técnico-económica y tipología de las explotaciones lecheras de la pampa argentina. FCV-LUZ 21:340-352.

González-Echeverría, J. 2012. Situación actual y perspectivas del sector lácteo costarricense. Una visión de la Cámara Nacional de Productores de Leche. In Memorias Congreso Nacional Lechero 2012. San Carlos, Costa Rica (en línea). Consultado 1 ene. 2013. Disponible en http://www.proleche.com/2012.aspx

Hair, JF; Anderson, RE; Tatham, RL; Black, W. 1998. Multivariate data analysis. 5 ed. New York, USA, Prentice Hall College Division. 768 p.

Holdridge, LR. 1987. Ecología basada en zonas de vida. Trad. por Humberto Jiménez Saa. San José, Costa Rica, IICA. 216 p.

Johnson, R; Wichern, D. 1998. Applied multivariate statistical analysis. 4 ed. New York, USA, Prentice Hall. 799 p.

Kirner, L; Ortner, KM; Hambrusch, J. 2007. Using technical efficiency to classify Austrian dairy farms. Die Bodenkultur 58:1-4.

Köbrich, C; Rehman, T; Khan, M. 2003. Typification of farming systems for constructing representative farm models: Two illustrations of the application of multivariate analyses in Chile and Pakistan. Agricultural Systems 76:141-157.

Martínez-García, CG; Dorward, P; Rehman, T. 2012. Farm and socio-economic characteristics of smallholder milk producers and their influence on technology adoption in Central Mexico. Tropical Animal Health and Production 44:1199-1211.

Mburu, LM; Wakhungu, JW; Kang'ethe, WG. 2007. Characterization of smallholder dairy production systems for livestock improvement in Kenya highlands. Livestock Research for Rural Development 19(8) (en línea). Consultado 1 ene. 2013. Disponible en http://www.lrrd.org/lrrd19/8/mbur19110.htm

Nainggolan, D; Termansen, M; Reed, MS; Cebollero, ED; Hubacek, K. 2011. Farmer typology, future scenarios and the implications for ecosystem service provision: a case study from south-eastern Spain. Regional Environmental Change (en línea). Consultado 1 ene. 2013. Disponible en http://link.springer.com/ article/10.1007/s10113-011-0261-6/fulltext.html

SAS (SAS Institute Inc, US). 2008. SAS/STAT® User's guide: Statistics. Version 9.2. Cary, NC. 7600 p.

SEPSA (Secretaría Ejecutiva de Planificación Sectorial Agropecuaria). 2012. Boletín estadístico agropecuario No. 22. San José, Costa Rica. 208 p. (Serie cronológica 2008-2011).

Serrano-Martínez, E; Giráldez-García, FJ; LavínGonzález, P; Bernués Jal, A; Ruiz-Mantecón, A. 2004a. Classification variables of cattle farms in the mountains of León, Spain. Spanish Journal of Agricultural Research 2:504-511.

Serrano-Martínez, E; Giráldez-García, FJ; Lavín-González, P; Bernués-Jal, A; Ruiz-Mantecón, A. 2004b. The identification of homogeneous groups of cattle farms in the mountains of León, Spain. Spanish Journal of Agricultural Research 2:512-523.

Smith, R; Moreira, V; Latrille, L. 2002. Caracterización de sistemas productivos lecheros en la $\mathrm{X}$ región de Chile mediante análisis multivariable. Agricultura Técnica 62:375-395.

Solano, C; Bernués, A; Rojas, F; Joaquín, N; Fernández, W; Herrero, M. 2000. Relationships between management intensity and structural and social variables in dairy and dual-purpose systems in Santa Cruz, Bolivia. Agricultural Systems 65:159-177.

Solano, C; León, H; Pérez, E; Herrero, M. 2003. The role of personal information sources on the decision-making process of Costa Rica dairy farmers. Agricultural Systems 76:3-18.

Srairi, MT; Lyobi, R. 2003. Tipología de los sistemas de producción de leche bovina en la región Periurbana de Rabat, Marruecos. Archivos de Zootecnia 52:4758.

Valerio-Cabrera, D; García Martínez, A; Acero de la Cruz, R; Castaldo, A; Perea, JM; Peinado, JM. 2004. Metodología para la caracterización y tipificación de sistemas ganaderos. España, Departamento de Producción Animal, Universidad de Córdoba. 9 p.

Vargas-Leitón, B. 2000. Bioeconomic modelling to support management and breeding of dairy cows in Costa Rica. Ph.D. thesis. The Netherlands, Wageningen University. 187 p. 
Vázquez-Martínez, M; Vargas-López, S; Zaragoza-Ramírez, JL; Bustamante-González, A; Calderón-Sánchez, F; Rojas-Álvarez, J; Casiano-Ventura, MA. 2009. Tipología de explotaciones ovinas en la sierra norte del estado de Puebla. Técnica Pecuaria en México 47:357-369.
Wattiaux, M. 2005. Mastitis, prevention and detection. In Dairy essentials, Chapter 24. Babcock Institute. p. 9396 (en línea). Consultado 10 mayo 2013. Disponible en http://babcock.wisc.edu/sites/default/files/de/en/ de_24.en.pdf 
